\title{
Randomized Trial of Volume Infusion During Resuscitation of Asphyxiated Neonatal Piglets
}

\author{
MYRA WYCKOFF, DAMIAN GARCIA, LINDA MARGRAF, JEFFREY PERLMAN, AND ABBOT LAPTOOK \\ Departments of Pediatrics [M.W., D.G.] and Pathology [L.M.], University of Texas Southwestern Medical Center, Dallas, Texas 75390; \\ Department of Pediatrics [J.P.], Weil Medical College at Cornell University, NY, New York 10021; Department of Pediatrics [A.L.], \\ Women \& Infants Hospital of Rhode Island/Brown Medical School Providence, Rhode Island 02905
}

\begin{abstract}
Despite its use, there is little evidence to support volume infusion (VI) during neonatal cardiopulmonary resuscitation (CPR). This study compares 5\% albumin (ALB), normal saline (NS), and no VI (SHAM) on development of pulmonary edema and restoration of mean arterial pressure (MAP) during resuscitation of asphyxiated piglets. Mechanically ventilated swine $(n=37$, age: $8 \pm$ $4 \mathrm{~d}$, weight: $2.2 \pm 0.7 \mathrm{~kg}$ ) were progressively asphyxiated until $\mathrm{pH}$ $<7.0, \mathrm{PaCO}_{2}>100 \mathrm{~mm} \mathrm{Hg}$, heart rate $(\mathrm{HR})<100 \mathrm{bpm}$, and MAP $<20 \mathrm{~mm} \mathrm{Hg}$. After $5 \mathrm{~min}$ of ventilatory resuscitation, piglets were randomized blindly to ALB, NS, or SHAM infusion. Animals were recovered for $2 \mathrm{~h}$ before euthanasia and lung tissue sampled for wet-to-dry weight ratio (W/D) as a marker of pulmonary edema. SHAM MAP was similar to VI during resuscitation. At $2 \mathrm{~h}$ postresuscitation, MAP of SHAM $(48 \pm 13 \mathrm{~mm} \mathrm{Hg})$ and ALB $(43 \pm 19$ $\mathrm{mm} \mathrm{Hg})$ was higher than NS $(29 \pm 10 \mathrm{~mm} \mathrm{Hg} ; p=0.003$ and 0.023 , respectively). After resuscitation, SHAM piglets had less pulmonary edema (W/D: $5.84 \pm 0.12$ versus $5.98 \pm 0.19 ; p=0.03$ ) and better dynamic compliance $(\mathrm{Cd})$ compared with ALB or NS (Cd: $1.43 \pm$ 0.69 versus $\left.0.97 \pm 0.37 \mathrm{~mL} / \mathrm{cm} \mathrm{H}_{2} \mathrm{O}, p=0.018\right)$. VI during resuscitation did not improve MAP, and acute recovery of MAP was poorer with NS compared with ALB. VI was associated with increased pulmonary edema. In the absence of hypovolemia, VI during neonatal resuscitation is not beneficial. (Pediatr Res 61: 415-420, 2007)
\end{abstract}

The American Academy of Pediatrics/American Heart Association Neonatal Resuscitation Program (NRP) recommends consideration of volume infusion using crystalloid or Onegative blood for neonates with obvious hypovolemic shock and for those not responding to ventilation, cardiac compressions, and epinephrine (1). 5\% Albumin (ALB) was removed from the recommendations in 2000, in part due to concerns that ALB may worsen pulmonary edema and increase mortality (2,3). Although guidelines for ALB use in the delivery room were changed, there are no randomized studies assessing the efficacy of any type of volume infusion during delivery room resuscitation of newborns. A recent retrospective study of near-term and term infants reported lower admission blood pressures and higher base deficits that persisted over the first

Received July 28, 2006; accepted November 2, 2006

Correspondence: Myra H. Wyckoff, M.D., Division of Neonatal-Perinatal Medicine, Department of Pediatrics, University of Texas Southwestern Medical Center at Dallas, 5323 Harry Hines Boulevard, Dallas, TX 75390-9063; e-mail: myra.wyckoff@ utsouthwestern.edu

This work was supported by an American Academy of Pediatrics Neonatal Resuscitation Program Research grant.

DOI: $10.1203 / p d r .0 b 013 e 3180332 \mathrm{c} 45$
$2 \mathrm{~h}$ of life for infants who received volume infusions compared with those that did not during delivery room cardiopulmonary resuscitation (CPR) (4). Due to the retrospective nature of the study, it was unclear whether volume infusion exacerbated the hypotension or whether its use was simply a marker for a more severe injury due to asphyxia. The infrequent and unexpected need coupled with the difficulty of obtaining informed consent for such studies has impeded the design and completion of rigorous randomized delivery room resuscitation trials. Thus, we designed a blinded, randomized, controlled trial to examine the risks and benefits of volume infusion during resuscitation of asphyxiated, hypotensive neonatal piglets whose cardiopulmonary compromise closely parallels that of infants who receive volume resuscitation in the delivery room.

Our primary hypothesis was that ALB administration would increase pulmonary edema (as evidenced by lung tissue wetto-dry weight ratio (W/D)) by $20 \%$ compared with normal saline (NS) or no volume infusion (SHAM). Additional hypotheses were that administration of ALB would adversely affect respiratory mechanics such as pulmonary dynamic compliance (Cd) but that volume infusion (NS and ALB) would be beneficial compared with SHAM in restoring MAP during resuscitation.

\section{METHODS}

This investigation was approved by the Institutional Review Board for Animal Research at The University of Texas Southwestern Medical Center at Dallas.

Surgical preparation. A total of 37 Yucatan miniature swine (weight: $2.2 \pm$ $0.7 \mathrm{~kg}$, postnatal age: $8 \pm 4 \mathrm{~d}$ ) were studied. All piglets were administered ketamine $[20 \mathrm{mg} / \mathrm{kg} \mathrm{i.m.]} \mathrm{as} \mathrm{premedication} \mathrm{and} \mathrm{then} \mathrm{were} \mathrm{instrumented} \mathrm{under}$ pentobarbital anesthesia of $10-15 \mathrm{mg} / \mathrm{kg}$ in an i.v. bolus followed by $5-10$ $\mathrm{mg} / \mathrm{kg} / \mathrm{h}$ with additional boluses to prevent spontaneous breathing. The lower doses were for younger animals to achieve appropriate anesthesia. All surgical sites were infiltrated with $1 \%$ Xylocaine (Steris Laboratories Inc., Phoenix, AZ). A tracheostomy was performed with placement of a $3.5-\mathrm{mm}$ endotracheal tube. The piglets were ventilated (Harvard Apparatus Rodent Respirator, model 680 , Millis, MA) with $70 \%$ nitrous oxide and $30 \%$ oxygen using rates of 60 breaths/min and tidal volume adjusted to achieve $\mathrm{PaCO}_{2}$ in the mid-40s $\mathrm{mm} \mathrm{Hg}$ range during the stabilization period. Catheters were positioned by aseptic technique in the right and left external jugular veins, the left internal jugular vein, the left common carotid artery, and the left femoral

\footnotetext{
Abbreviations: ALB, 5\% albumin; Cd, dynamic compliance; CPR, cardiopulmonary resuscitation; HR, heart rate; MAP, mean arterial pressure; NRP, Neonatal Resuscitation Program NS, normal saline; SHAM, no volume infusion; W/D, wet-to-dry weight ratio
} 
artery. After catheter placement, the inspired gas was changed to $50 \%$ nitrogen and $50 \% \mathrm{O}_{2}$. The piglet's body temperature was maintained between $38^{\circ}$ and $39^{\circ} \mathrm{C}$ using a thermal blanket wrapped around the body and circulating warm water $\left(40^{\circ}-45^{\circ} \mathrm{C}\right)$ through the blanket. Heart rate (HR) and mean arterial pressure (MAP) were monitored continuously using a pressure transducer (Gould Statham, Houston, TX) and recorded on a Beckman Dynograph Recorder (Fullerton, $\mathrm{CA}$ ). Continuous end-tidal $\mathrm{CO}_{2}\left(\mathrm{ETCO}_{2}\right)$ measurements were obtained using a $\mathrm{CO}_{2} \mathrm{SMO}$ PLUS Respiratory Profile Monitor (Novametrix, Wallingford, CT) that uses mainstream near-infrared sampling with a neonatal sensor that adds minimal $(0.5 \mathrm{~mL})$ dead space to the overall ventilator circuit and limits the risk of $\mathrm{CO}_{2}$ retention (5). The capnometer was calibrated using the internal reference cells, according to the manufacturer's instructions.

Experimental protocol (Fig. 1). After instrumentation, animals were allowed to stabilize for $60 \mathrm{~min}$ before acquisition of baseline measurements. Asphyxia was induced by changing ventilatory gases to $7.5 \% \mathrm{CO}_{2}$ and $5.3 \%$ $\mathrm{O}_{2}$, and the ventilator rate was reduced by 10 breaths/min every 15 min until the following parameters were achieved: $\mathrm{pH}<7.0, \mathrm{PaCO}_{2}>100 \mathrm{~mm} \mathrm{Hg}, \mathrm{MAP}$ $<20 \mathrm{~mm} \mathrm{Hg}$, and $\mathrm{HR}<100 \mathrm{bpm}$. Asphyxia was reversed by initiating resuscitation with increased ventilation using baseline ventilator settings and $100 \% \mathrm{O}_{2}$. Animals that continued to have $\mathrm{HR}<60 \mathrm{bpm}$ despite $30 \mathrm{~s}$ of improved ventilation received $30 \mathrm{~s}$ of closed-chest cardiac compressions followed by $0.01 \mathrm{mg} / \mathrm{kg}$ i.v. epinephrine for continued bradycardia or asystole. After $5 \mathrm{~min}$ of resuscitation, piglets were randomized with blinding to 10 $\mathrm{mL} / \mathrm{kg}$ i.v. over $5 \mathrm{~min}$ of NS, ALB, or SHAM. Following a 2-min infusion pause, a second bolus was given over $5 \mathrm{~min}$. Two boluses were given because a recent clinical report noted a mean of two $10-\mathrm{mL} / \mathrm{kg}$ volume infusions per infant who received volume infusions during delivery room CPR (4). Animals were recovered without additional medications or volume infusions for $2 \mathrm{~h}$ before euthanasia.

Measurements. Serial arterial blood gases with simultaneous HR, MAP, lactate, glucose, hematocrit, and $\mathrm{O}_{2}$ content were measured. Plasma concentrations of lactate were determined by quantitative enzymatic determination assay (Sigma Chemical Co., St. Louis, MO). Plasma glucose concentrations were determined by enzymatic colorimetric determination (Sigma Chemical Co). $\mathrm{O}_{2}$ content was measured using a Radiometer Hemoximeter (model OSM3, Copenhagen, DK). The volume of blood removed at each sampling was $1 \mathrm{~mL}$. After removal of plasma for lactate and glucose, the packed red blood cells were returned to the animal to maintain hematocrit. Pulmonary $\mathrm{Cd}$ was measured using the $\mathrm{CO}_{2} \mathrm{SMO}$ PLUS Respiratory Profile Monitor (Novametrix). After euthanasia, the thorax was opened and the lungs visually inspected. Postmortem lung tissue was harvested for the W/D as the marker of pulmonary edema as well as histologic examination in the following manner: five pieces of lung tissue from the left lung were weighed upon removal and subsequently dried in an Napco Vacuum Oven (model 5831, Precision Scientific, Chicago, IL) at $-20 \mathrm{~cm} \mathrm{H}_{2} \mathrm{O}$ and $80^{\circ} \mathrm{C}$ for $72 \mathrm{~h}$ (6). The dry weights of the lung tissue were then determined and the lung W/D calculated [(wet weight - dry weight)/dry weight]. The mean W/D was used as the measure of pulmonary edema. The right lung was used for histologic analysis. The right lower lobe was inflation fixed in 10\% formalin (Fisher Scientific, Fairlawn, NJ) before sectioning. The remainder was formalin fixed, and representative sections were routinely processed for light microscopy. Hematoxylin and eosin-stained slides were examined by a reviewer (L.M.) blinded to the resuscitation protocol. Lung sections were examined systematically for hemorrhage, congestion, evidence of respiratory epithelial injury, alveolar edema, and inflammation. The amount of alveolar hemorrhage was estimated by recording the percentage of blood-filled alveolar spaces. The degree of intravascular congestion was also noted. Interstitial hemorrhage was graded 0 to +3 based on the extent of extravasated interstitial blood $(+1$

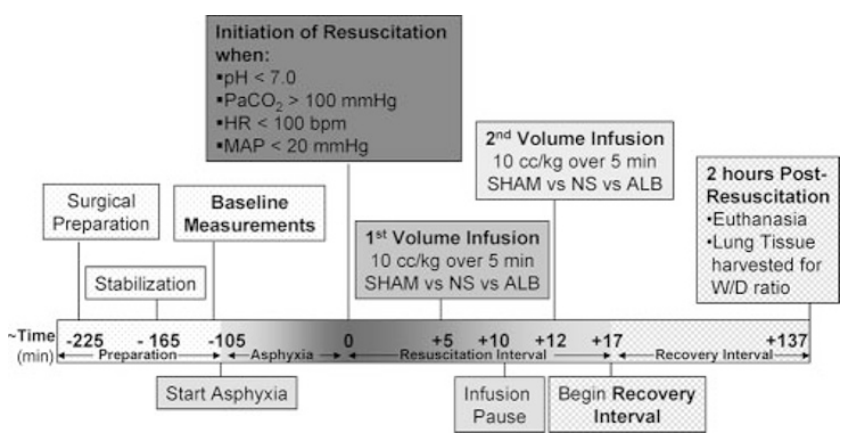

Figure 1. Experimental protocol. focal, +3 extensive). The degree of edema was graded 0 to +3 based on the presence of acellular eosinophilic fluid within the alveolar spaces.

Randomization/allocation procedure. Piglets were randomly assigned to ALB, NS, or SHAM in blocks of nine using a random permutation table. Treatment was allocated using sealed sequential envelopes. Investigators were blinded to treatment group by an opaque covering placed over the infusion syringes and infusion catheter. Volume syringes were filled and covered by the technician (D.G).

Sample size calculations. Sample size was based on whether ALB boluses cause increased pulmonary edema compared with NS or SHAM during volume resuscitation. The primary outcome variable was the W/D. Based on W/D data of $6.5 \pm 0.9$ from preliminary study animals $(n=6), 11$ animals were needed in each group to detect a $20 \%$ increase in pulmonary edema with a type I error rate of 5\% and a type II error rate of $20 \%$ by means of one-way analysis of variance (ANOVA).

Statistical methods. Data are presented as mean \pm SD. Statistical analysis was completed using SigmaStat 3.0 (SPPSS, Chicago, IL). One-way ANOVA was used for comparisons of SHAM and NS, SHAM and ALB, and ALB and NS. A $t$ test was used for comparisons of SHAM versus volume infusion (NS and ALB). A Bonferroni correction was used for multiple comparisons. A $p$ value of $\leq 0.05$ was considered statistically significant.

\section{RESULTS}

At baseline, there were no differences between treatment groups in age, weight, sex, $\mathrm{HR}, \mathrm{MAP}, \mathrm{pH}, \mathrm{PaCO}_{2}$, lactate, glucose, hematocrit, $\mathrm{O}_{2}$ content, or pulmonary Cd (Table 1). At initiation of resuscitation, all treatment groups had similar degrees of severe asphyxia with hypotension and bradycardia (Table 2). Severe asphyxia reduced pulmonary Cd compared with baseline in all treatment groups to a similar degree.

For all treatment groups, the majority of piglets (22/37, $60 \%$ ) responded to effective ventilation and oxygenation alone

Table 1. Piglet characteristics at baseline

\begin{tabular}{lccc}
\hline & $\begin{array}{c}\text { SHAM } \\
(n=12)\end{array}$ & $\begin{array}{c}\text { NS } \\
(n=12)\end{array}$ & $\begin{array}{c}\text { ALB } \\
(n=13)\end{array}$ \\
\hline Age (d) & $9 \pm 5$ & $8 \pm 4$ & $8 \pm 4$ \\
Weight $(\mathrm{kg})$ & $2.25 \pm 0.88$ & $2.12 \pm 0.62$ & $2.11 \pm 0.76$ \\
$\%$ Male & $58 \%$ & $33 \%$ & $54 \%$ \\
HR (bpm) & $167 \pm 21$ & $171 \pm 18$ & $176 \pm 20$ \\
Mean arterial blood & $68 \pm 8$ & $64 \pm 10$ & $71 \pm 9$ \\
$\quad$ pressure (mm Hg) & & & \\
pH & $7.35 \pm 0.03$ & $7.34 \pm 0.04$ & $7.36 \pm 0.04$ \\
Paco $(\mathrm{mm} \mathrm{Hg})$ & $43 \pm 5$ & $44 \pm 4$ & $43 \pm 3$ \\
Lactate $(\mathrm{mM})$ & $1.41 \pm 0.3$ & $1.25 \pm 0.3$ & $1.43 \pm 0.4$ \\
Glucose $(\mathrm{mg} \%)$ & $114 \pm 28$ & $117 \pm 16$ & $106 \pm 23$ \\
$\mathrm{Hematocrit}(\%)$ & $31 \pm 1$ & $30 \pm 5$ & $32 \pm 5$ \\
$\mathrm{O}_{2}$ content $(\mathrm{vol} \%)$ & $13.0 \pm 0.7$ & $12.2 \pm 1.9$ & $13.3 \pm 0.9$ \\
$\mathrm{Cd}\left(\mathrm{mL} / \mathrm{cm} \mathrm{H}_{2} \mathrm{O}\right)$ & $1.8 \pm 0.4$ & $1.5 \pm 0.5$ & $1.7 \pm 0.6$ \\
\hline
\end{tabular}

Table 2. Piglet characteristics at initiation of resuscitation

\begin{tabular}{lccc}
\hline & $\begin{array}{c}\text { SHAM } \\
(n=12)\end{array}$ & $\begin{array}{c}\text { NS } \\
(n=12)\end{array}$ & $\begin{array}{c}\text { ALB } \\
(n=13)\end{array}$ \\
\hline $\begin{array}{l}\text { Time to resuscitation } \\
\quad(m i n)\end{array}$ & $101 \pm 27$ & $108 \pm 26$ & $108 \pm 19$ \\
HR (bpm) & $77 \pm 21$ & $77 \pm 24$ & $65 \pm 28$ \\
Mean arterial blood & $15 \pm 3$ & $15 \pm 3$ & $16 \pm 2$ \\
pressure (mm Hg) & & & \\
$\mathrm{pH}$ & $6.74 \pm 0.10$ & $6.65 \pm 0.12$ & $6.67 \pm 0.12$ \\
$\mathrm{Paco}(\mathrm{mm} \mathrm{Hg})$ & $133 \pm 20$ & $141 \pm 22$ & $142 \pm 21$ \\
Lactate $(\mathrm{mM})$ & $7.1 \pm 1.5$ & $7.8 \pm 1.9$ & $7.7 \pm 2.1$ \\
$\mathrm{Glucose}^{(\mathrm{mg} \%)}$ & $298 \pm 122$ & $178 \pm 115$ & $241 \pm 144$ \\
$\mathrm{Hematocrit}(\%)$ & $32 \pm 3$ & $30 \pm 5$ & $32 \pm 3$ \\
$\mathrm{O}_{2}$ content reduction $(\%)$ & $71 \pm 11$ & $80 \pm 9$ & $73 \pm 16$ \\
$\mathrm{Cd}\left(\mathrm{mL} / \mathrm{cm} \mathrm{H}_{2} \mathrm{O}\right)$ & $1.3 \pm 0.5$ & $1.1 \pm 0.4$ & $1.2 \pm 0.4$ \\
\hline
\end{tabular}


Table 3. Type of resuscitation required to achieve return of $H R$

\begin{tabular}{lllll}
\multicolumn{5}{c}{$>100 \mathrm{bpm}$} \\
& $\begin{array}{c}\text { SHAM } \\
(n=12)\end{array}$ & $\begin{array}{c}\text { NS } \\
(n=12)\end{array}$ & $\begin{array}{c}\text { ALB } \\
(n=13)\end{array}$ & $p$ \\
\hline Ventilation alone & $6(50 \%)$ & $9(75 \%)$ & $7(54 \%)$ & $\mathrm{ns}$ \\
Ventilation + CPR & $1(8 \%)$ & $0(0 \%)$ & $0(0 \%)$ & $\mathrm{ns}$ \\
Ventilation + CPR + EPI & $4(33 \%)$ & $2(16 \%)$ & $4(33 \%)$ & $\mathrm{ns}$ \\
Asystolic despite ventilation + & $1(8 \%)$ & $1(8 \%)$ & $2(16 \%)$ & $\mathrm{ns}$
\end{tabular}

$\mathrm{CPR}+\mathrm{EPI}$

ns, not significant; EPI, epinephrine.
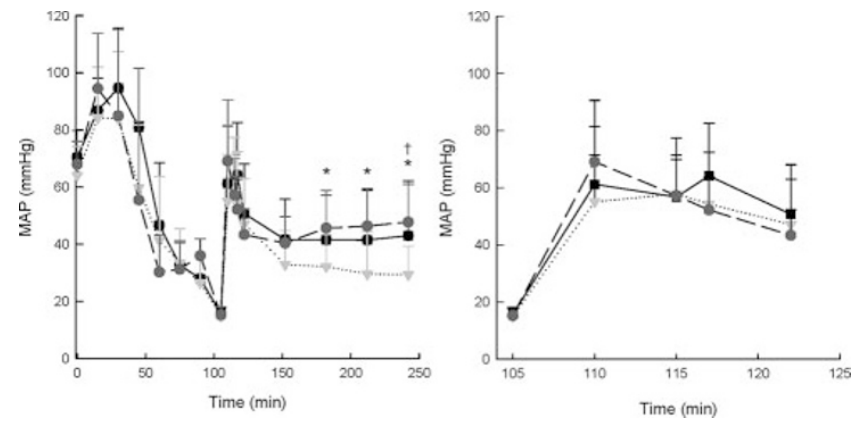

Figure 2. All piglets $(n=37), \longrightarrow$ ALB, $\cdots \cdots$ NS, - SHAM. MAP $v s$ time during the entire experiment (left) and during the resuscitation (right). ${ }^{*} p<0.05$ SHAM $v s$ NS; $\dagger p<0.05$ ALB $v s$ NS. The $p$ value determined via ANOVA uncorrected for multiple comparisons.

(Table 3). The remaining 15 of 37 (40\%) became asystolic despite ventilation with $100 \% \mathrm{O}_{2}$. Fourteen of 15 of piglets who became asystolic required epinephrine in an attempt to achieve a HR $>100 \mathrm{bpm}$ of which 10 responded. Only one asystolic piglet (SHAM group) responded to the addition of compressions without epinephrine. There was no difference between treatment groups in the number of piglets that remained asystolic despite resuscitation.

With initiation of resuscitation, blood pressure increased in all three groups between 0 and $5 \mathrm{~min}$; however, the infusion of either ALB or NS (between 5 and $10 \mathrm{~min}$ ) did not improve MAP compared with SHAM (Fig. 2, bottom). During the second infusion (between 12 and $17 \mathrm{~min}$ ), again there was no improvement in MAP for all three groups. MAP continued to decline in the NS group such that by $2 \mathrm{~h}$ post-resuscitation, the MAP of the SHAM and ALB groups was significantly higher than that of the NS group. (Fig. 2, top). SHAM piglets did not differ from NS or ALB piglets in $\mathrm{pH}, \mathrm{HR}, \mathrm{PaCO}_{2}$ or lactate (Fig. 3), $\mathrm{ETCO}_{2}$, glucose, or hematocrit, although the direction of effect was for SHAM piglets to have the highest blood pressure, highest $\mathrm{pH}$, and least lactate at the end of $2 \mathrm{~h}$ post-resuscitation (Table 4). Although not significant, the direction of effect was for SHAM piglets to have improvement in $\mathrm{Cd}$ and less pulmonary edema compared with NS and ALB piglets. There was no difference in lung histology between groups (alveolar hemorrhage, interstitial hemorrhage, or congestion).

When SHAM piglets were compared with all piglets that received volume infusions (NS and ALB), SHAM piglets had significantly less pulmonary edema and better pulmonary $\mathrm{Cd}$ at $2 \mathrm{~h}$ post-resuscitation (Table 5).

To further examine the safety of volume infusion when only minimal resuscitation was required, the subgroup of piglets
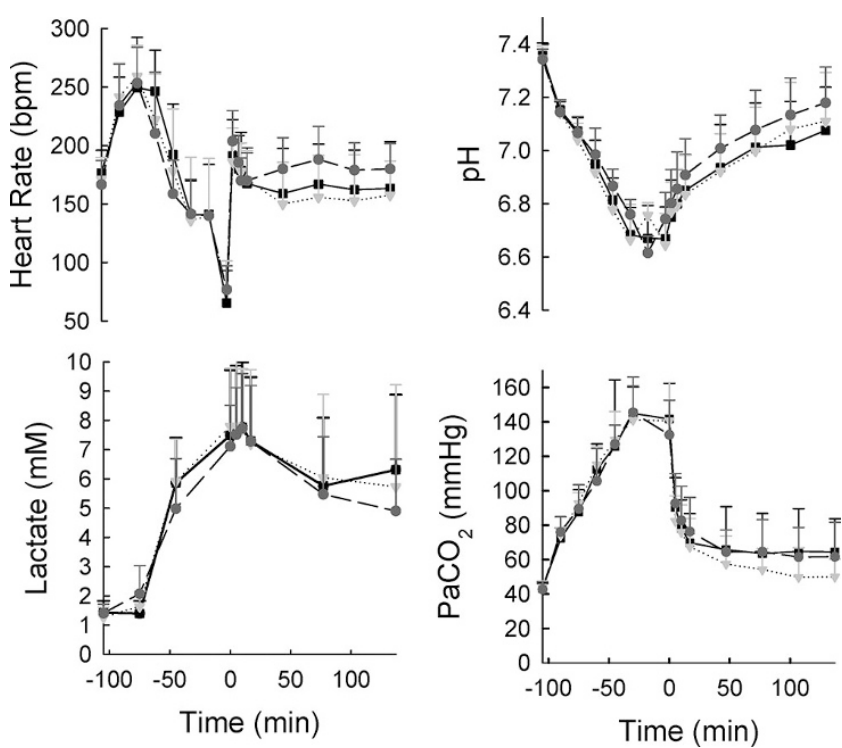

Figure 3. All piglets $(n=37), \longrightarrow$ ALB, $\cdots \cdots$ NS, $\bullet$ SHAM. HR (top left), $\mathrm{pH}$ (top right), lactate (bottom left), and $\mathrm{PaCO}_{2}$ (bottom right) vs time during the entire experiment.

that had resolution of hypotension and bradycardia with ventilation alone was compared according to whether they received SHAM or volume infusion during resuscitation (Table 6). Ventilation responders that received SHAM infusion had higher blood pressure at the end of the 2-h postresuscitation period compared with volume infusion recipients. Ventilation responders that received volume infusions had poorer pulmonary $\mathrm{Cd}$ by the end of the 15 -min resuscitation protocol that persisted $2 \mathrm{~h}$ later compared with SHAM recipients. In addition, ventilation responders that received volume infusions had increased pulmonary edema compared with SHAM (W/D: $6.01 \pm 0.23$ versus $5.80 \pm 0.11, p=0.045$ ).

\section{DISCUSSION}

This is the first randomized study to examine the role of volume infusion during resuscitation in a newborn model of asphyxia that approximates delivery room experience. The salient findings were that volume infusion resulted in significantly increased pulmonary edema and decreased pulmonary compliance compared with animals without volume infusion. At $2 \mathrm{~h}$ after resuscitation, animals resuscitated with NS had significantly lower MAP compared with ALB or SHAM recipients. In addition, piglets that received volume infusions (either ALB or NS) as part of the randomized protocol despite previous resolution of hypotension and bradycardia with improved ventilation and oxygenation also had lower blood pressure $2 \mathrm{~h}$ after resuscitation as well as increased pulmonary edema and decreased pulmonary compliance compared with SHAM.

Current NRP recommendations suggest consideration of volume infusion in the delivery room for neonates with obvious hypovolemic shock and for those not responding to ventilation, cardiac compressions, and epinephrine whose lack of response may be due to unrecognized hypovolemia (1). The preferred solution for volume expansion is one that is readily 
Table 4. Piglet characteristics at 2 hours post-resuscitation

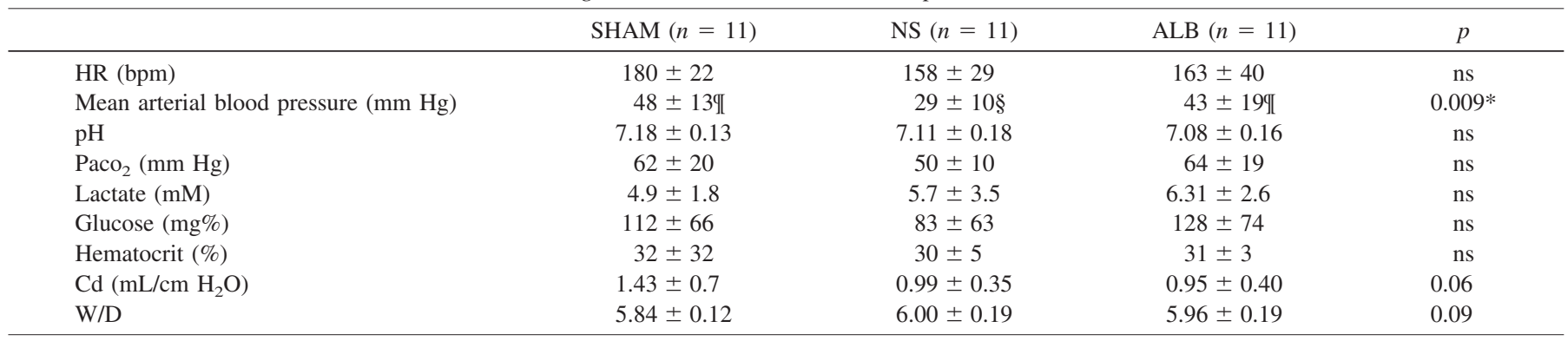

* Different symbols represent significant differences between groups as determined by ANOVA for multiple groups.

Table 5. Pulmonary edema of SHAM versus volume infusion (ALB and NS) recipients

\begin{tabular}{lccc}
\hline & SHAM & Volume & \\
& $(n=11)$ & $(n=22)$ & $p$ \\
\hline $\mathrm{W} / \mathrm{D}$ & $5.84 \pm 0.12$ & $5.98 \pm 0.19$ & 0.03 \\
$\mathrm{Cd}\left(\mathrm{mL} / \mathrm{cm} \mathrm{H}_{2} \mathrm{O}\right)$ & $1.43 \pm 0.69$ & $0.97 \pm 0.37$ & 0.02 \\
\hline
\end{tabular}

available, remains within the intravascular space, has isoosmolar characteristics, and carries a low risk of infection or sensitivity reaction (7). ALB-containing solutions are not part of the recommendations because of increased cost, limited availability, a theoretical risk of infectious disease, and in particular a previous observed association with increase mortality in a large meta-analysis of ALB versus crystalloid use across the indications of hypovolemia, burns, and hypoalbuminemia of primarily adult studies (3). Two neonatal trials of hypotensive preterm infants in the neonatal intensive care unit $(8,9)$ were included along with 28 adult trials. Several of the included adult studies suggested that patients who received ALB had worse pulmonary outcomes (10-12).

At a molecular level, pulmonary edema develops when there are imbalances between the intravascular and extravascular hydrostatic pressure and intravascular and extravascular oncotic pressure in the lung. Colloids such as ALB were initially postulated to be beneficial compared with crystalloid because of their theoretical potential to increase intravascular oncotic pressure as well as provide volume expansion. Several fetal and newborn animal studies demonstrated that hypoxia and asphyxia are associated with transvascular fluid flux into the lung $(13,14)$. Although this appears to be due more to increases in pulmonary microvascular pressure than increased microvascular permeability (13-15), ALB has been shown to leak significantly out of the vasculature during significant hypoxia and asphyxia (13). ALB is a relatively small protein (molecular weight 70,000, effective molecular radius $=36 \AA$ ) and it is conceivable that molecules this size could traverse the space between pulmonary endothelial cells (16). It has been postulated that as ALB extravasates into the interstitium, it might increase the interstitial oncotic pressure, leading to further fluid movement out of the capillary (17), thus paradoxically increasing pulmonary edema. Paradoxical increased edema was found in several vascular beds in a trial comparing ALB to NS in a piglet model of bowel obstruction (18).

Based on the previous data and physiologic plausibility, we hypothesized that ALB infusion during resuscitation would cause more pulmonary edema than NS and reduce pulmonary $\mathrm{Cd}$; however, this was not the case. ALB did not cause more pulmonary edema than NS. Our findings are in concordance with a recent large multicenter, randomized, blinded, controlled trial of ALB versus NS for fluid resuscitation in adult intensive care patients that demonstrated no difference in death nor for secondary outcomes including days of mechanical ventilation or MAP; however, patients who received ALB required less study fluid administration and had lower HRs (19). In our study, infusion of either volume expander during resuscitation from severe asphyxia resulted in increased pulmonary edema and decreased pulmonary compliance compared with SHAM infusion. Thus, at a time when adequate ventilation and oxygenation are critical to effective transition from fetal to postnatal circulation and consequently to stabilization in the delivery room, one should view infusion with either volume expander with caution. In particular, piglets that responded to ventilation and oxygenation (and thus would not have met strict NRP criteria for volume infusion) were subsequently harmed by volume infusion as noted by decreased

Table 6. Piglets that responded to ventilation alone with resolution of hypotension and bradycardia: SHAM versus volume infusion (ALB and NS) recipients

\begin{tabular}{|c|c|c|c|}
\hline & SHAM $(n=6)$ & Volume $(n=16)$ & $p$ \\
\hline MAP at control $(-105 \mathrm{~min})(\mathrm{mm} \mathrm{Hg})$ & $64 \pm 4$ & $65 \pm 10$ & ns \\
\hline MAP at start of resuscitation $(0 \mathrm{~min})(\mathrm{mm} \mathrm{Hg})$ & $17 \pm 2$ & $16 \pm 2$ & $\mathrm{~ns}$ \\
\hline MAP at end of resuscitation $(17 \mathrm{~min})(\mathrm{mm} \mathrm{Hg})$ & $44 \pm 7$ & $48 \pm 17$ & ns \\
\hline $\mathrm{Cd}$ at control $(-105 \mathrm{~min})\left(\mathrm{mL} / \mathrm{cm} \mathrm{H}_{2} \mathrm{O}\right)$ & $1.90 \pm 0.55$ & $1.64 \pm 0.51$ & ns \\
\hline $\mathrm{Cd}$ at start of resuscitation $(0 \mathrm{~min})\left(\mathrm{mL} / \mathrm{cm} \mathrm{H}_{2} \mathrm{O}\right)$ & $1.50 \pm 0.45$ & $1.22 \pm 0.42$ & ns \\
\hline $\mathrm{Cd}$ at end of resuscitation $(17 \mathrm{~min})\left(\mathrm{mL} / \mathrm{cm} \mathrm{H}_{2} \mathrm{O}\right)$ & $1.57 \pm 0.49$ & $1.06 \pm 0.37$ & 0.016 \\
\hline
\end{tabular}


pulmonary compliance, more pulmonary edema, and more hypotension. Decreased pulmonary compliance compared with SHAM was noted immediately after the volume infusions even with stringent adherence to infusing slowly over 5 min as is recommended by NRP (1).

One might be willing to take the risk of increased pulmonary edema if volume infusion resulted in improved blood pressure during or after resuscitation; however, this was not the case. In this nonhypovolemic model of severe asphyxia, there was no improvement in blood pressure with either ALB or NS during the resuscitation. During the infusion of volume, blood pressure trended down for all three groups. Possible explanations include that volume-mediated acute distention of the right atrium led to release of atrial natriuretic peptide with resultant vasodilation (20) or possibly that intravascular sheer stress caused by the acute volume bolus led to nitric oxide- or prostacyclin-mediated vasodilation (21). Several studies in newborn animals and humans have shown that asphyxia can lead to a large placental transfusion into the baby (22-24). Thus, the majority of asphyxiated infants requiring intensive resuscitation in the delivery room are not hypovolemic $(4,25)$ similar to the piglet model used in these experiments. The neonatal heart operates at the top end of the Frank-Starling curve and is not as effective as the more mature heart at increasing cardiac output in the face of increased preload under normal conditions (26-28). Multiple studies have demonstrated profound myocardial effects after perinatal asphyxia, including radiographic evidence of failure, ischemic changes on electrocardiography, elevated troponin levels, and echocardiographic changes in contractility (29-33). Such observations of myocardial dysfunction after asphyxia support the possibility that volume infusions during delivery room resuscitation may be detrimental and exacerbate poor cardiac output when hypovolemia is not present. Similar to retrospective clinical observations (4), piglets that received NS had hypotension post-resuscitation with no increase in HR, suggesting that the normal compensatory mechanisms to maintain cardiac output in the face of hypotension were not present.

The blood pressure findings of this study suggest that ALB may be more effective than NS when used during delivery room resuscitation as evidenced by MAP $2 \mathrm{~h}$ after resuscitation. This differs from current NRP recommendations (1) that favor crystalloid infusion unless emergent O-negative blood is available. The findings are also different from those of three small randomized, controlled trials of NS versus ALB for the treatment of hypotension in acutely ill newborns in the NICU in which NS was found to be equivalent to ALB in improving blood pressure $(9,34,35)$. Our findings may reflect acute increased oncotic pressure after ALB infusion compared with NS. It is possible that the acidity of NS infusion caused further myocardial depression ( $\mathrm{pH}$ of $\mathrm{NS}=5.55 \pm 0.25$ versus $\mathrm{pH}$ of ALB $=7.07 \pm 0.09$ ). The most salient observation, however, is that neither was better than sham either during the actual resuscitation or in the 2-h recovery period.

Our current study is unique because it is the first experimental neonatal study to compare different volume expanders during resuscitation for cardiopulmonary collapse from asphyxia using neonatal resuscitation recommendations. The progressive nature of the insult leading to cardiovascular collapse is likely more similar to the human experience of profound mixed metabolic and respiratory acidemia found in babies who receive volume infusion in the delivery room (4) compared with other asphyxial models that simply clamp the endotracheal tube and await the rapid onset of asystole $(36,37)$. The neonatal piglet is a reasonable physiologic model for this type of research in that the size and cardiovascular system are similar to those of the human. There are limitations in extrapolating to human newborns because the model includes animals that have already transitioned from fetal to neonatal physiology, are sedated/anesthetized, and have less potential variability in blood volume. However, despite these limitations, the data are still potentially relevant because the distribution of cardiac output in the fetus and posttransitional neonate during asphyxial episodes are qualitatively similar (38-40). In addition, responsiveness and reactivity of the cerebral circulation to factors that modulate cerebral perfusion (like hypoxia) qualitatively remain intact under barbiturate anesthesia $(41,42)$. An additional limitation of the study is that volume was infused at $5 \mathrm{~min}$ of resuscitation whether or not the animal met the restrictive NRP recommendations for volume infusion. However, it is likely that this occurs often in the clinical setting as well. The short 2 -h observational interval provides no information regarding blood pressure for later time periods after resuscitation that might be different.

In conclusion, the data in this prospective, randomized, blinded, neonatal piglet trial support the concept that volume infusion as part of intensive resuscitation for asphyxiainduced hypotension and bradycardia increases pulmonary edema, decreases pulmonary $\mathrm{Cd}$, and does not improve blood pressure either during the resuscitation or during a 2-h postresuscitation interval compared with no SHAM. In addition, ALB did not lead to worse pulmonary edema compared with NS as hypothesized, but rather both types of fluids were equally detrimental compared with SHAM infusion. Volume infusion conferred no blood pressure advantage during resuscitation, and, of concern, NS infusion led to significantly lower blood pressures during the 2-h postresuscitation interval. Randomized clinical trials are the next logical step to appropriately address this question in the newborn. Given the rarity of the need for intensive resuscitation when the principles of effective ventilation in the delivery room are applied, this will need to be a large multicenter design but one that is worth the effort given the potential harm suggested by this trial. Until such a clinical trial is accomplished, the use of volume resuscitation in the delivery room should be reserved for only those infants with a strong suspicion of hypovolemia as the cause for their cardiovascular collapse.

Acknowledgments. The authors are indebted to Karen Kirby for preparing this manuscript. 


\section{REFERENCES}

1. Kattwinkel J 2006 Textbook of Neonatal Resuscitation 5th ed. American Academy of Pediatrics/American Heart Association, Elk Grove, IL pp 6-9, 6-22

2. Kattwinkel J, Niermeyer S, Nadkarni V, Tibballs J, Phillips B, Zideman D, Van Reempts P, Osmond M 1999 ILCOR advisory statement: resuscitation of the newly born infant. An advisory statement from the pediatric working group of the International Liaison Committee on Resuscitation. Circulation 99:1927-1938

3. [No authors listed] 1998 Human albumin administration in critically ill patients: a systematic review of randomized controlled trials. Cochrane Injury Group Albumin Reviewers. BMJ 317:235-240

4. Wyckoff MH, Perlman JM, Laptook AR 2005 Use of volume expansion during delivery room resuscitation in near-term and term infants. Pediatrics 115:950-955

5. Kirpalani H, Kechagias S, Lerman L 1991 Technical and clinical aspects of capnography in neonates. J Med Eng Technol 15:154-161

6. Raj JU, Bland RD, Lai-Fook SJ 1986 Microvascular pressures measured by micropipettes in isolated edematous rabbit lungs. J Appl Physiol 60:539-545

7. Niermeyer S 2006 Volume Resuscitation: Crystalloid versus Colloid. Clin Perinatol 33:133-140

8. Greenough A, Emery E, Hird MF, Gamsu HR 1993 Randomised controlled trial of albumin infusion in ill preterm infants. Eur J Pediatr 152:157-159

9. So KW, Fok TF, Ng PC, Wong WW, Cheung KL 1997 Randomised controlled trial of colloid or crystalloid in hypotensive preterm infants. Arch Dis Child Fetal Neonatal Ed. 76:F43-F46

10. Goodwin CW, Dorethy J, Lam V, Pruitt BA 1983 Randomized trial of efficacy of crystalloid and colloid resuscitation on hemodynamic response and lung after following thermal injury. Ann Surg 197:520-531

11. Virgilio RW, Rice CL, Smith DE, James DR, Zarins CK, Hobelmann CF, Peters RM 1979 Crystalloid vs colloid resuscitation: is one better? Surgery 85:129-139

12. Weaver DW, Ledgerwood AM, Lucas CE, Higgins R, Bouwman DL, Johnson SD 1978 Pulmonary effects of albumin resuscitation for severe hypovolemic shock. Arch Surg 113:387-392

13. Adamson TM, Boyd RD, Hill JR, Normand IC, Reynolds EO, Strang LB 1970 Effect of asphyxia due to umbilical cord occlusion in the foetal lamb on leakage of liquid from the circulation and on permeability of lung capillaries to albumin. J Physiol 207:493-505

14. Bressack MA, Bland RD 1980 Alveolar hypoxia increases lung fluid filtration in unanesthetized newborn lambs. Circ Res 46:111-116

15. Bland RD 1983 Edema formation in the lungs and its relationship to neonatal respiratory distress. Acta Paediatr Scand Suppl 305:92-99

16. O’Brodovich HM, Stalcup SA, Pang LM, Lipset JS, Mellins RB 1981 Bradykinin production and increased pulmonary endothelial permeability during acute respiratory failure in unanesthetized sheep. J Clin Invest 67:514-522

17. Metildi LA, Shackford SR, Virgilio RW, Peters RM 1984 Crystalloid versus colloid in fluid resuscitation of patients with severe pulmonary insufficiency. Surg Gynecol Obstet 158:207-212

18. Rowe MI, Arango A 1976 Colloid versus crystalloid resuscitation in experimental bowel obstruction. J Pediatr Surg 11:635-643

19. Finfer S, Bellomo R, Boyce N, French J, Myburgh J, Norton R SAFE Study Investigators $2004 \mathrm{~A}$ comparison of albumin and saline for fluid resuscitation in the intensive care unit. N Engl J Med 350:2247-2256

20. Suttner SW, Boldt J 2004 Natriuretic peptide system: physiology and clinical utility. Curr Opin Crit Care 10:336-341

21. Busse R, Fleming I 1995 Regulation and functional consequences of endothelial nitric oxide formation. Ann Med 27:331-340
22. Linderkamp O, Versmold HT, Messow-Zahn K, Müller-Holve W, Riegel KP, Betke K 1978 The effect of intrapartum and intrauterine asphyxia on placental transfusion in premature and full-term infants. Eur J Pediatr 127:91-99

23. Oh W, Omori K, Emmanouilides GC, Phelps DL 1975 Placenta to lamb fetus transfusion in utero during acute hypoxia. Am J Obstet Gynecol 122:316-322

24. Yao AC, Lind J 1972 Blood volume in the asphyxiated term neonate. Biol Neonate 21:199-209

25. Roberton NR 1997 Use of albumin in neonatal resuscitation. Eur J Pediatr $156: 428-431$

26. Rudolph AM 1985 Distribution and regulation of blood flow in the fetal and neonatal lamb. Circ Res 57:811-821

27. Pladys P, Wodey E, Betremieux P, Beuchee A, Ecoffey C 1997 Effects of volume expansion on cardiac output in the preterm infant. Acta Paediatr 86:1241-1245

28. Agata Y, Hiraishi S, Oguchi K, Misawa H, Horiguchi Y, Fujino N, Yashiro K, Shimada N 1991 Changes in left ventricular output from fetal to early neonatal life. J Pediatr 119:441-445

29. Anderson PA, Kleinman CS, Lister G, Talner NS 2004 Cardiovascular function during development and the response to hypoxia. In: Polin RA, Fox WW, Abman SH (eds) Fetal and Neonatal Physiology, 3rd ed WB Saunders, Philadelphia, pp. 635-669.

30. Cabal LA, Devaskar U, Siassi B, Hodgman JE, Emmanouilides G 1980 Cardiogenic shock associated with perinatal asphyxia in preterm infants. J Pediatr 96:705-710

31. Trevisanuto D, Picco G, Doglioni N, Altinier S, Zaninotto M, Zanardo V 2006 Cardiac troponin I in asphyxiated neonates. Biol Neonate 89:190-193

32. DiSessa TG, Leitner M, Ti CC, Gluck L, Coen R, Friedman WF 1981 The cardiovascular effects of dopamine in the severely asphyxiated neonate. J Pediatr 99:772-776

33. Bucciarelli RL, Nelson RM, Egan EA, Eitzman DV, Gessner IH 1977 Transient tricuspid insufficiency of the newborn: A form of myocardial dysfunction in stressed newborns. Pediatrics 59:330-337

34. Emery EF, Greenough A, Gamsu HR 1992 Randomised controlled trial of colloid infusions in hypotensive preterm infants. Arch Dis Child 67:1185-1188

35. Oca MJ, Nelson M, Donn SM 2003 Randomized trial of normal saline versus 5\% albumin for the treatment of neonatal hypotension. J Perinatol 23:473-476

36. Jasani MS, Nadkarni VM, Finkelstein MS, Mandell GA, Salzman SK, Norman ME 1994 Effects of different techniques of endotracheal epinephrine administration in pediatric porcine hypoxic-hypercarbic cardiopulmonary arrest. Crit Care Med 22:1174-1180

37. Berg RA, Otto CW, Kern KB, Hilwig RW, Sanders AB, Henry CP, Ewy GA 1996 A randomized, blinded trial of high-dose epinephrine versus standard-dose epinephrine in a swine model of pediatric asphyxial cardiac arrest. Crit Care Med 24:1695-1700

38. Behrman RE, Lees MH, Peterson EN, De Lannoy CW, Seeds AE 1970 Distribution of the circulation in the normal and asphyxiated fetal primate. Am J Obstet Gynecol 108:956-969

39. Cohn HE, Sacks EJ, Heymann MA, Rudolph AM 1974 Cardiovascular responses to hypoxemia and acidemia in fetal lambs. Am J Obstet Gynecol 120:817-824

40. Leffler CW, Busija DW, Beasley DG, Fletcher AM, Green RS 1986 Effects of indomethacin on cardiac output distribution in normal and asphyxiated piglets. Prostaglandins 31:183-190

41. Hohimer AR, Bissonnette JM 1989 Effects of cephalic hypotension, hypertension, and barbiturates on fetal cerebral flood flow and metabolism. Am J Obstet Gynecol 161:1344-1351

42. Donegan JH, Traystman RJ, Koehler RC, Jones MD Jr, Rogers MC 1985 Cerebrovascular hypoxic and autoregulatory responses during reduced brain metabolism. Am J Physiol 249:H421-H429 